\title{
Proceeding Paper \\ Life Cycle Assessment of 2.0 MW Horizontal Axis Wind Turbine for Sustainability Analysis ${ }^{\dagger}$
}

\author{
Rabia Hassan ${ }^{1, *(1)}$, Muhammad Mahboob ${ }^{2}\left(\mathbb{D}\right.$, Zubair Ahmed Jan ${ }^{3}$ and Muhammad Ashiq 2,4 \\ 1 College of Engineering and Sciences, Institute of Business Management, Karachi 75190, Pakistan \\ 2 Department of Mechanical Engineering, University of Engineering and Technology, Taxila 47050, Pakistan; \\ Muhammad.Mahboob14140@gmail.com (M.M.); Muhammad.ashiq@uos.edu.pk (M.A.) \\ 3 Department of Machines and Transport, Poznan University of Technology, 60-965 Poznan, Poland; \\ ahmedzubairjan1@gmail.com \\ 4 Department of Mechanical Engineering, College of Engineering and Technology, University of Sargodha, \\ Sargodha 40100, Pakistan \\ * Correspondence: rabia.hassan@iobm.edu.pk \\ + Presented at the 1st International Conference on Energy, Power and Environment, Gujrat, Pakistan, 11-12 \\ November 2021.
}

Citation: Hassan, R.; Mahboob, M.; Jan, Z.A.; Ashiq, M. Life Cycle Assessment of 2.0 MW Horizontal Axis Wind Turbine for Sustainability Analysis. Eng. Proc. 2021, 12, 60. https://doi.org/10.3390/ engproc2021012060

\section{Academic Editor:}

Muhammad Tanveer

Published: 6 January 2022

Publisher's Note: MDPI stays neutral with regard to jurisdictional claims in published maps and institutional affiliations.

Copyright: (c) 2022 by the authors. Licensee MDPI, Basel, Switzerland. This article is an open access article distributed under the terms and conditions of the Creative Commons Attribution (CC BY) license (https:// creativecommons.org/licenses/by/ $4.0 /)$.

\begin{abstract}
The world is increasingly experiencing unanticipated catastrophic events because of the impact of greenhouse gasses. The two major issues with the conventional energy system are unsustainability and global warming, which are extremely harmful for the climate. The core objective of this study is a compilation of the findings related to a life cycle assessment of horizontal axis wind turbines in regard to sustainable development. Sustainability aspects and concerns have been studied and reported in terms of the life cycle of wind energy technology. This article focused on energy consumed during the life of the 2.0 MW wind turbine, mostly in the production of primary materials, processes, and maintenance-related transport phase. The turbine's overall energy produced $1,750,000 \mathrm{kWh}$ throughout a 20-year life. Over a 20year lifespan, the overall energy produced by the turbine is approximately $32 \%$ more than the energy needed to construct, and the destination for the turbine materials is a landfill at the end of the turbine's life. For a $40 \%$ wind turbine power ratio, with the wind turbine materials delivered to landfill at the end of the turbine's life, the electricity payback period is around 10 months, and for recycled materials it is 6 months. The comparison is also done for the wind turbine materials which are sent to landfill with and without recycling.
\end{abstract}

Keywords: LCA; wind turbine; energy; landfill; recycle

\section{Introduction}

Energy plays a significant role in daily life. Nowadays, conventional sources are mostly utilized as energy. The major concerns regarding non-renewable sources of energy are sustainability and global warming [1]. The greatest approach to overcome these problems is sustainable energy. The natural resource that does not impact the atmosphere is wind. Most countries understand the importance of wind energy and utilize it as the predominant renewable energy source, due to its low cost as compared to other renewable resources of energy [2]. Wind energy is generated through converting the KE (Kinetic Energy) of ambient air into mechanical energy. The turbines used for transferring kinetic energy into mechanical energy are the horizontal axis wind turbine (HAWT) and vertical axis wind turbine (VAWT) [3].

\section{Horizontal Axis Wind Turbine। HAWT}

The horizontal axis wind turbine (HAWT) is commonly used for higher production volume, requiring massive investment, and occupying more installation space relative to the vertical axis wind turbine (VAWT). To produce electricity, the rotational axis of the 
HWAT is parallel to the direction of wind [4]. The cost of production of the HWAT is lower, while producing a higher amount of electricity; as such, the performance of the HAWT is greater than the VAWT.

\section{Life Cycle Analysis of Wind Turbine Material}

To generate materials, feedstock and ore are extracted from the resources of the earth. These materials are processed into items which are utilized and recycled when their lives end, a fraction of which can join a recycling loop, with the remaining dedicated to combustion or a landfill. At every stage in this phase, energy and resources are depleted with a corresponding penalty of $\mathrm{NOx}$, Sox, $\mathrm{CO}_{2}$, and other pollutants, gases and heat, and solid and liquid waste. Previous research studies on the life cycle of wind turbines have analyzed the following: energy and resource flows in the procurement of raw materials; manufacturing and processing; storage and delivery (transport, cooling); use; repair and maintenance; and recycling [5].

Life cycle analysis (LCA), or eco audit, and techniques selected to direct the design, are as follows: The first phase is to build an estimated, but adequate discrimination tool to distinguish among alternative options [6]. There is a range of research levels, starting from basic eco-screening of a collection of restricted or unacceptable products and methods to a complete LCA, including costs and time overheads [7]. Selecting a single quantifier of eco-stress is the second step. The final phase is to distinguish the inputs of the life stages since the dominant one is contingent on subsequent behavior. If it is related to the production of material, then the choice of material with minimal "energy embodied" is considered.

\section{Wind Turbine 2.0 MW LCA Results}

This life cycle analysis describes the use of energy and carbon emissions within five stages (materials, production, transport, usage, and disposal) throughout the product's life [8]. Wind turbine (WT) power generation is sustainable and clean energy, but in the life cycle of WTs, sources of energy are used and pollution is generated during the development, production period, usage, transport, and disposal of raw materials. To evaluate the effect of wind turbine power production, all components required for the generation of electricity, including the rotor, nacelle, transmission, foundation, and tower, should be included in the study.

The bill of material for a $2 \mathrm{MW}$ land base wind turbine is illustrated Figure 1. Energy used throughout turbine's life (approx. 20 years), mainly in the production of basic materials, production procedures, and maintenance-related transportation. The utilized energy for the transportation of large and small components of the wind turbine, as well as the energy used during servicing, was estimated from the assessment and servicing visit information contained in the Vestas report $[9,10]$.

The total demand of energy and carbon dioxide impact at each stage of End of Life (EoL), for landfill and recycling, respectively, are summarized in Figure 2. The analysis of the life cycle of a wind turbine (WT) was conducted at first in the scenario wherein recycling materials from the WT were sent to landfill. Then, the analysis was conducted wherein WT materials were sent to be recycled. Higher energy is accumulated, and high concentrations of $\mathrm{CO}_{2}$ are emitted into the environment throughout the wind turbine components' primary material manufacturing. The other dominating phase is the method of production where the turbine components are delivered to the landfill at the EoL point for the turbine.

The findings also demonstrate the effects of the components being recycled at the completion of the wind turbine's life. In the case where the wind turbine materials at the EoL are sent to landfill, the energy required for the disposal of these materials is $218,260,000 \mathrm{KJ}$, and $13,096 \mathrm{Kg}$ of carbon dioxide is exposed to the environment. However, if the WT materials are recycled, the cumulative energy required is $6,851,200,000 \mathrm{KJ}$, which constitutes $54.8 \%$ of the overall energy being retained at the completion of the material's 
life. By recycling wind turbine materials, a total decrease of $495,917 \mathrm{Kg}$ in $\mathrm{CO}_{2}$ emissions is achieved.

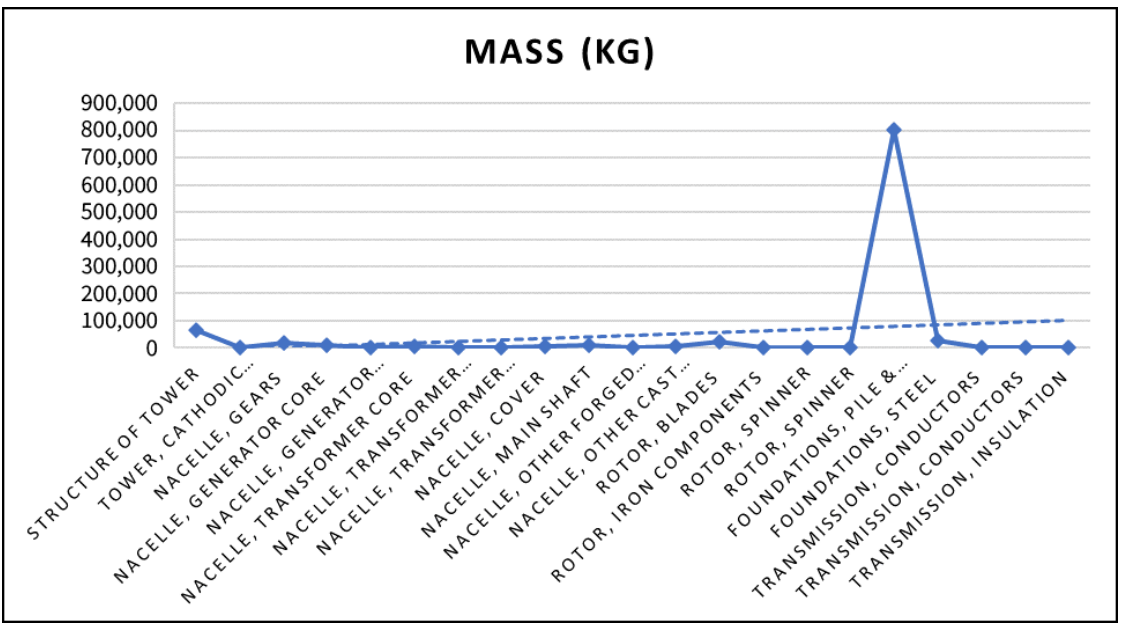

Figure 1. Wind Turbine of 2MW Bill of Material.
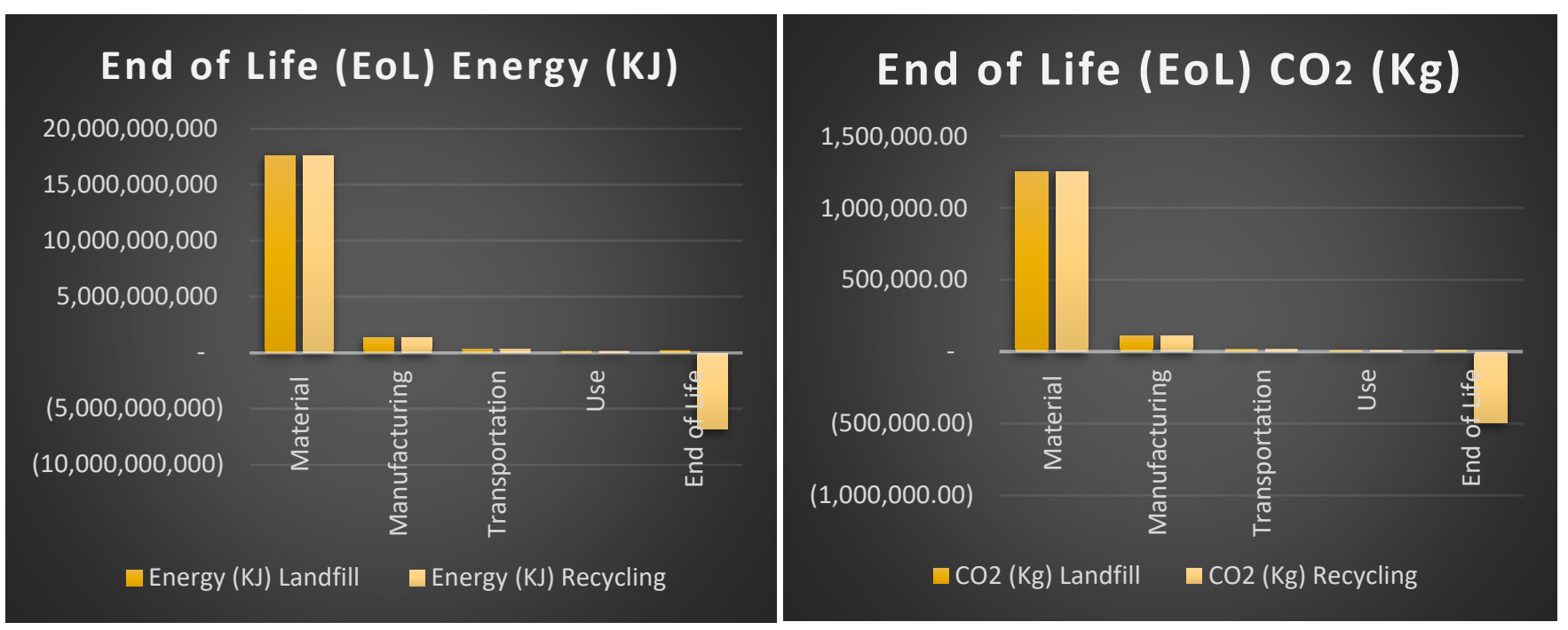

Figure 2. End of Life Energy and $\mathrm{CO}_{2}$ with and without Recycling.

Figure 3 presents the overall view of wind turbine output energy, payback time, and energy construction at End of Life (EoL), for recycling and landfill, respectively.

The turbine operates at $40 \%$ average capacity in the optimistic outcome. Over a 20 -year lifespan, the overall energy produced by the turbine is approximately $32 \%$ more than the needed energy to construct and operate it, if the materials of the turbine are sent to landfill at the turbine's EoL. If the components are reused, the turbine's cumulative energy produced over a lifespan of 20 years is around 50 times the energy needed to construct and operate it. For a 40\% WT power ratio, if the WT materials are delivered to landfill at turbine's end life, the electricity payback period is around 10 months and for recycled materials it is 6 months. 


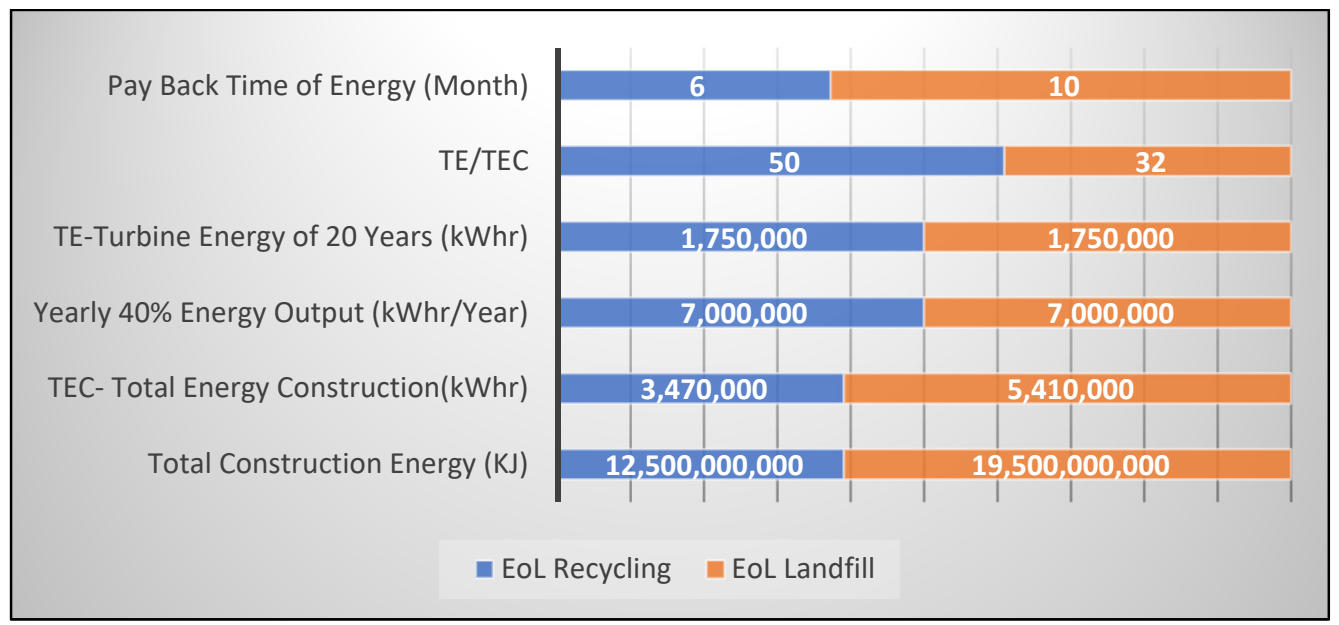

Figure 3. Wind Turbine Output Energy, Payback Time, and Energy Construction.

\section{Conclusions}

The effective future strategy development of energy creation is safer and more effective, and the use of modern and green sources of energy will play a significant role. Wind turbine power generation is a clean and sustainable technology; however, wind turbines use sources of energy from a life cycle approach and generate pollution throughout the raw material processing, production processes, transference of large and small components of WT, repair, and parts disposal at the end of the turbine's life. To assess the WT energy production impacts, all parts of the turbine required for the development of electricity, including the rotor, nacelle, tower, base, and transmission, must be involved in the study.

\section{References}

1. Usman, M.; Makhdum, M.S.A.; Kousar, R. Does financial inclusion, renewable and non-renewable energy utilization accelerate ecological footprints and economic growth? Fresh evidence from 15 highest emitting countries. Sustain. Cities Soc. 2021, 65, 102590. [CrossRef]

2. Rathod, P.; Shah, K.; Desai, H.; Shah, J.; Professor, A. A Review on Combined Vertical Axis Wind Turbine. Int. J. Innov. Res. Sci. Eng. Technol. 2007, 3297, 5748-5754. [CrossRef]

3. Sarathi, Y.; Patel, K.; Tirkey, A.; Sen, P.K.; Sharma, R. Study on Wind Turbine and Its Aerodynamic Performanc. Int. J. Mech. Eng. Rob. Res. 2015, 4, 249-256.

4. Rolin, V.; Porté-Agel, F. Wind-tunnel study of the wake behind a vertical axis wind turbine in a boundary layer flow using stereoscopic particle image velocimetry. J. Phys. Conf. Ser. 2015, 625. [CrossRef]

5. Walachowicz, F.; Bernsdorf, I.; Papenfuss, U.; Zeller, C.; Graichen, A.; Navrotsky, V.; Rajvanshi, N.; Kiener, C. Comparative Energy, Resource and Recycling Lifecycle Analysis of the Industrial Repair Process of Gas Turbine Burners Using Conventional Machining and Additive Manufacturing. J. Ind. Ecol. 2017, 21, S203-S215. [CrossRef]

6. Ghenai, C. Sustainable Engineering and Eco Design. In Sustainable Development_Energy, Engineering and TechnologiesManufacturing and Environment; University of Sharjah: Sharjah, United Arab Emirates, 2012.

7. Veliu, G.; Caslli, S. The material-energy binomial in epicenter of eco-design. The case of materials for the 'Glina' bottled water. In Proceedings of the 24th International Conference on Efficiency, Cost, Optimization, Simulation and Environmental Impact of Energy Systems, ECOS 2011, Novi Sad, Serbia, 4-7 July 2011; pp. 2790-2802.

8. United States Environmental Protection Agency. Solid Waste Management and Greenhouse Gases: A Life-Cycle Assessment of Emissions and Sinks; United States Environmental Protection Agency: Washington, DC, USA, 2006.

9. Martínez Domínguez, M. Technical Description. Nord. Energy 2021, 9, 6. Available online: http://www.udgvirtual.udg.mx/ paakat/index.php/paakat/rt/printerFriendly/519/661 (accessed on 3 January 2022).

10. Vestas. Life Cycle Assessment of Offshore and Onshore Sited Wind Turbines Vestas Wind Systems A/S, Alsvij 21, 8900 Randus, Denmark. 2005. Available online: https:/ / www.vestas.com/ (accessed on 3 January 2022). 